Invited review for the 2020 Electrochemical Engineering section of Current Opinion in Electrochemistry.

(M.E. Orazem, Editor)

Nov. 05, 2019

\title{
The Electrodeposition of Composite Coatings: Diversity, Applications and Challenges
}

Frank C. Walsh ${ }^{\mathrm{a}, *}$ Shuncai Wang, ${ }^{\mathrm{a}}$ Nan Zhou ${ }^{\mathrm{a}, \mathrm{b}}$

a. Electrochemical Engineering Laboratory and national Centre for Advanced Tribology, Department of Mechanical Engineering, Faculty of Engineering and Physical Sciences, University of Southampton, Southampton, SO17 1BJ UK.

b. Present address: Ultra Precision Motion Ltd., Unit D2 Chelworth Industrial Estate, Cricklade, Swindon, Wilts. SN6 6HE UK.

* Author for correspondence; f.c.walsh@ soton.ac.uk

\begin{abstract}
A wide range of coatings can be produced by incorporating particles into an electrodeposit. The matrix may be a metal, conductive polymer or conductive ceramic while the particle can be metallic, polymeric, ceramic or combinations of spheroidal, irregular or layered inclusions. Nanostructured, gradient, multilayer and sandwich layer deposit further widen possibilities. Electrochemical approaches to the deposition of composite coatings offer the benefits of good control over deposition rate (hence thickness), coating composition and deposit properties. Both faradaic electrodeposition and electrophoresis are usually involved. This review focuses on nanosized inclusions in a metal matrix over the last two decades. Interactions between bath composition, particle dispersion, operational variables and resultant deposit properties are poorly documented. Our understanding of the mechanism of composite deposition remains patchy, despite progress and computer models are scarce. Electrode geometry, electrolyte hydrodynamics and current distribution remain poorly treated. Markets in electronics, surface engineering, aerospace, corrosion protection and electrochemical energy conversion have been stimulated by newer uses as self-cleaning, superhydrophobic and biocompatible surfaces. Challenges to be met by further R \& D are prioritised.
\end{abstract}

Keywords: electroplating; inclusions; electrolyte additives; mechanism; metal matrix composites; modelling; surfactants; 


\section{Highlights}

- Composite electrodeposition involves faradaic and electrophoretic processes.

- Self-lubricating and superhydrophobic surfaces can be achieved.

- Uses span aerospace, energy conversion, corrosion protection and tribology.

- Improvements in knowledge of mechanism and multi-physics modelling are awaited.

- Critical needs for development of the technology are identified.

\section{Contents}

1. Introduction

2. Fundamentals, mechanism and models

3. Practical considerations and the importance of operational variables

4. Traditional and developing applications in engineering

5. Conclusions

\section{Introduction}

Many materials can be combined in composite coatings applied by electrodeposition, both anodic and cathodic. This huge family of composite coatings includes ceramic particles in a polymer matrix, polymer-metal sandwich layers and gradient, multilayer or nanostructured deposits [1]. The host matrix can be a metal, alloy, ceramic or polymer while particles can be spheroidal, acicular, plate-like, layered or core-shell, of a size from sub $\mathrm{mm}$ down to several $\mathrm{nm}[2]$. Here, the focus is on cathodic deposition of micrometre and nanometre sized ceramic or polymer particles (of diverse shape) in a metal matrix from one bath in a single step. The electrodeposition of composite coatings, also referred to as 'inclusion plating', 'codeposition of metals and particles' or 'electrocodeposition', dates back to the early 1900s. Over the last decade, intense activity has been stimulated by the availability of new materials and the search for applications of graphenes. 
Many reviews of the science and technology of electrodeposited composite coatings have appeared over the last two decades. Two reviews have focussed on electrochemical aspects [35]. The scope of previous contributions was summarised in an extensive review by Walsh in 2014, which also considers materials engineering and surface finishing aspects [6]. Nanoparticle composite deposits and their features have been stressed [7]. Other reviews have considered deposit properties in more detail, e.g. [8-11]. Examples of recent or specialised reviews include Ni-ceramic nanoparticle deposits [12]. Graphene related particle in metal deposits [13], Ni-P alloy particle coatings [14] and Ni-Co-particle [15] composite coatings.

The present contribution attempts to provide a concise summary of fundamental knowledge mechanism and models (section 2) and the technology involved (section 3). Particular attention is drawn to the shortcomings of models to describe the mechanism of particle codeposition and the limitations of mathematical models. Diverse applications of the resulting deposits are illustrated in section 4; particular attention is paid to recent developments. Following a general summary in section 5, which highlights developments over the last decade, aspects demanding further R \& D are highlighted in section 6.

The number of parameters involving in composite electrodeposition, together with their mutual interaction, complicate our appreciation of important factors in composite electrodeposition (Figure 1). In modelling studies, it is particularly important to adopt a well-considered and quantitative approach to experimental design, with results and their weighting being analysed by proven, quantitative methods. Unfortunately, this requirement is neglected in the vast majority of studies and 'optimisation' of conditions is misused to mean 'the best result 
observed under limited experimental conditions', i.e., optimisation of a particular feature, such as the particle content of deposits, morphology or deposit hardness.

\section{Fundamentals, Mechanism and Models}

\subsection{Fundamental deposition}

The codeposition of particles and metal by electrodeposition is shown schematically in Figure 2a). Complicating factors include the interactions among process conditions, operational parameters and deposit properties (Figure 2b). Critical factors for successful composite deposits are summarized in Figure 2c) and aspects affecting the mechanism of composite electrodeposition and the results sought from a multi-physics model are considered in Figure 2d).

The relative roles of Faradaic electrodeposition and electrophoretic particle movement to the cathode, i.e. catophoresis, are not well understood in the vast literature on electrodeposited composite layers. The overall rate of metal deposition is given by Faraday's laws of electrolysis $[16,17]:$

$$
\frac{d x}{d t}=\frac{\phi j M}{\rho z F}
$$

where $j$ is the current density $\left(\mathrm{A} \mathrm{cm}^{-2}\right), x$ is the deposit thickness $(\mathrm{cm}), \rho$ is the density of the metal deposit $\left(\mathrm{g} \mathrm{cm}^{-3}\right), z$ is the number of electrons in the electrode process (dimensionless), $F$ is the Faraday constant $\left(96485 \mathrm{C} \mathrm{mol}^{-1}\right), t$ is the time (s), $\phi$ which is $<1$ or $=1$, is the current efficiency for metal deposition [dimensionless] and $M$ is the molar mass of deposited metal. 
The overall rate of electrophoretic deposition of particles on the cathode can be related to operational conditions by the empirical Hamaker law, which describes the rate of uniform coating thickness, $x$ with time, $t$ due to movement of dispersed particles in colloidal solution during electrophoresis:

$$
\frac{d x}{d t}=\varepsilon \mu \rho c_{w} \frac{d E}{d x}
$$

where $\mu$ is the electrophoretic mobility of a charged species $\left(\mathrm{m}^{2} \mathrm{~V}^{-1} \mathrm{~s}^{-1}\right), t$ the time $[\mathrm{s}], d E / d x$ the potential field gradient $\left(\mathrm{V} \mathrm{m}^{-1}\right), c_{w}$ is the concentration of particles in the electrolyte and $\varepsilon$ an efficiency factor $(<1)$ which allows for the fact that not all solids arriving at the electrode are deposited on the surface of the workpiece $[18,19]$.

\subsection{Mechanism of composite electrodeposition and multi-physics models}

Earlier reviews, e.g., [3-6] have summarised the strengths and weaknesses of suggested models to describe the electrodeposition of composite coatings. An important 1972 contribution by Guglielmi [20] considers charge transfer controlled metal deposition with adsorption of particles. It continues to be regularly cited, despite its severe limitations in not considering mass transfer, particle entanglement, electrosorption and electrokinetics [6]. Important contributions to a more complete model have been made by Celis. Roos and Buelens who proposed an improved, 5-step mechanism [21] and Valdes in 1987 [22] who proposed a 'perfect sink' model with the assumption of infinitely fast kinetics, all particles arriving within a critical distance of the cathode surface being incorporated into the deposit. Useful critiques of available models were published in 2001 [4] and 2015 [23], which highlight the failure of models to quantitatively describe the effect of operational variables, such as current density and electrolyte flow on deposit particle loading. 
The deposit composition is controlled by the relative rates of particle incorporation and metal matrix growth. Any contemporary mechanism describing the process of composite electrodeposition must consider the following aspects:

1. The rate of particle transport to the cathode is governed by both electrophoresis (migration of charged particles driven by an electric field gradient) and convective-diffusion mass transport (movement driven by concentration and velocity gradients).

2. The deposition rate of metal is governed by Faraday's laws of electrolysis, allowing for a known current efficiency due to side reactions. The current may be charge transfer, mixed or mass transfer controlled [6].

3. The rate of electrokinetic deposition of particles can be described by the Hamaker equation; the particle charge, cell potential and interelectrode gap are important.

4. The particle charge, when dispersed in solution changes to a neutral adsorbed particle on the cathode surface.

5. The particles must stick to the cathode surface, initially by (electro)sorption, rather than glancing off it due to lack of incorporation into the growing metal matrix coupled with excess momentum and high shear.

6. Any contemporary model must be able to predict the particle loading in the deposit, for a given bath composition, known operating conditions, fixed electrode geometry and chosen bath agitation.

\section{Practice and the importance of operational variables}

While the technology of electroplating is classical, composite electroplating technology has received much less attention $[16,17]$. Figure 3 summarises major operational variables which affect the deposit. In this section, some important aspects are highlighted. 
The choice of electrode and cell geometry often follows tradition and convenience rather than electrochemical engineering needs. In industry, common choices are:

a) an open tank with bottom fed educator flow of electrolyte or use of air sparging, perhaps with gentle cathode reciprocation.

b) a horizontally rotating, perforated barrel, for small, regularly shaped components such as fastenings, washers and bushes, which tumble in a satisfactory manner.

c) a custom cell, such as electrolyte flow through an annular gap to electroplate internal cylinder walls or flow through a rectangular channel to accommodate flat, rectangular components, or an RDE stack to electroplate multiple, uniform, flat circular components, such as grinding, polishing and cutting wheels.

On the laboratory bench, vertical, parallel plate electrodes are commonly mounted at a fixed interelectrode distance in a beaker on top of a magnetic stirrer hotplate. Despite the convenience of this arrangement, the flow and mass transfer to the cathode surface are poorly defined and difficult to reproduce or scale-up, being subject to complex, e.g., vortex, secondary flows and being dependent on the location, and shape of the stirrer follower, not just its rotation speed. More consideration needs to be given to the use of well-defined, controllable flow achieved via, e.g., the RDE, RCE, channel flow or the submerged wall jet electrode.

While ionic liquids are starting to be introduced, most laboratory studies and industrial practice use aqueous electrolytes, the Watts bath [24] being particularly common for $\mathrm{Ni}$ composite coatings. It is important to realise that the electrolyte in composite electrodeposition is a 2phase, dilute slurry. This has implications for ohmic drop, viscosity and electrokinetic effects but this is rarely appreciated. In the case of nanoparticles, the electrolyte is a nanofluid having different mass transfer properties, as shown in RCE studies [25]. 
Several studies have used the RDE to provide a controlled flow and mass transport to the cathode surface. It must be realised, however, that the RDE is difficult to scale-up, prone to marked edge effects and normally operates as a smooth electrode in laminar flow. Practical electroplating processes normally involve developing or turbulent or flow, making the RCE a more appropriate device, despite difficulties in preparing cylindrical surfaces for deposition [6, 26] and corrosion studies [27] has been extensively reviewed.

The dispersion of particles in the electrolyte depends on sufficient electrode/electrolyte movement and electrostatic repulsion between particles of having like-charges. A surfactant can aid dispersion by modifying surface charge via adsorption. A net positive charge also encourages electrophoretic movement of particles to the cathode. Excess surfactant should be avoided since it can act as a modifier of metal electrocrystallisation, which can increase internal stress in deposits. An adsorption isotherm, i.e., a plot of concentration of surfactant adsorbed on the particles $v s$. the concentration added to the electrolyte at a fixed temperature establishes the degree of surface adsorption as a plateau region and can indicate suitable surfactant levels but such plots rarely appear in the electroplating literature. A stable dispersion can often be achieved by premixing lighter or hydrophobic particles, e.g., PTFE, graphite, $\mathrm{MoS}_{2}$ or $\mathrm{WS}_{2}$, in a small volume of electrolyte, using a high shear mixer then adding the slurry to the electrolyte to achieve the required composition, as recently highlighted for $\mathrm{Ni}-\mathrm{MoS}_{2}$ electrolytes [28]. Figure 4 indicates the importance of preparing a stable dispersion of particles in the electrolyte using shear mixing.

Traditional studies have often focused on electrolyte composition, temperature and current density as major variables or been limited to the effects of e.g., $\mathrm{pH}$, current density and stirring 
rate on one electrolyte. The importance of electrolyte additives to both particle dispersion/incorporation into the deposit and the metal matric characteristics have been poorly considered, many studies being limited to a single additive at a fixed initial concentration.

\section{Traditional and developing applications}

Traditional uses of composite electrodeposition include $\mathrm{Ni}-\mathrm{SiC}$ or $\mathrm{Co}-\mathrm{WC}$ for wear resistance, abrasion and cutting, Ni-PTFE, Ni-MoS ${ }_{2}$ or $\mathrm{Ni}-\mathrm{WS}_{2}$ for combined self-lubrication/wear resistance and c) $\mathrm{Cu}$-graphite or $\mathrm{Ni}$-graphite for controlled electrical conductivity. Recent applications are considered in this section. From an engineering tribology perspective, wear and corrosion resistance are particularly important characteristics of electrodeposited coatings. Despite many studies, quantitative comparisons are made difficult by shortcomings in the literature.

In corrosion and protection studies, it is important to:

a) specify the type of corrosion and its location,

b) state the half-cell electrode reactions and consider how the reactants and products affect reaction rate,

c) consider the factors controlling the rate of corrosion, and

d) validate rapid, indirect laboratory corrosion measurements from polarization data (gained using menu driven software suites) against weight loss or solution analysis over extended times.

During the tribological evaluation of coatings, it vital to:

a) state the shape, size, composition and position of the counterbody, 
b) quantify the load on the component under test and its time dependence,

c) consider various types of environment, speed of motion and load to evaluate tribological performance, then

d) evaluate the importance of time, stop-start and cycling on results.

In all testing, the temperature, composition and the flow velocity of the environment are critical.

\subsection{Tribological coatings}

Electrodeposited multifunctional and nanostructured coatings are important in many tribological applications [11]. Environmental pressure has ensured that hard chromium replacement coatings have dominated coatings for engineering tribology. $\mathrm{Ni}$ deposits containing $\mathrm{SiC}$ particles, particularly nanosized ones, have remained intensively studied for their wear resistance, Over 20 surfactants (cationic, non-ionic and anionic) have been evaluated for $\mathrm{Ni}-\mathrm{SiC}$ composite electrodeposition from an agitated, modified Watts nickel electrolyte at $60^{\circ} \mathrm{C}$ using a current density of $10-100 \mathrm{~mA} \mathrm{~cm}^{-2}$ [29]. Nickel coatings containing welldispersed, submicron $(150-500 \mathrm{~nm}) \mathrm{SiC}$ particles were electrodeposited from an electrolyte containing $10 \mathrm{~g} \mathrm{dm}^{-3} \mathrm{SiC}$ at a current density of $6 \mathrm{~A} \mathrm{dm}^{-2}$. Over 20 surfactants including anionic, cationic, and non-ionic types were evaluated for their influence on the surface and tribological properties of the nanocomposite coatings. A surfactant concentration of $0-3 \mathrm{~g} \mathrm{dm}^{-3}$ was used. Coating microhardness, surface coefficient of friction (COF) and abrasive wear performance of the deposits were investigated. The surfactants affected the loading of silicon carbide nanosized particles in the coating ( 5 to $54 \mathrm{vol} .-\%$ ) and altered the surface microstructure 
from a matte to a bright surface finish and from porous to nodular, compact coatings. The coatings showed improved resistance to abrasive wear compared to a plain nickel deposit by a factor of 2-20. Ni-SiC composite coatings were deposited on the inner surfaces of cathodic cylinders using electrolyte circulated from a holding tank [30]. The arrangement is proposed for large-scale use but the authors seem unaware that flow through a concentric cylinder in the batch recycle mode has been in industrial use for electrodeposition of cylinder liners since the 1970s. Other particles incorporated in nickel deposits are $\mathrm{B}_{4} \mathrm{C}$ [31], h-BN [32] and WC [36].

The main applications of solid lubricants and coatings are in the space industry and/or extreme environments and their relative merits have been considered by NASA [33]. Recent examples include $\mathrm{MoS}_{2}, \mathrm{WS}_{2}$, graphene related materials and their mixtures, usually incorporated in a nickel electrodeposit. Effective particle dispersion via high-shear mixing has been used to prepare particle-electrolyte dispersions prior to electrodepositing $\mathrm{Ni}-\mathrm{MoS}_{2}$ composite coatings for improved tribological performance [33]. Electroplating of non-fluorinated superhydrophobic Ni-WC or Ni-WS 2 composite coatings with high abrasive resistance [34]. Self-lubricating Ni-P-MoS 2 coatings have also been examined [35]. The advantages of a more corrosion resistant, Ni-Co alloy matrix for soft lubricant particles has been demonstrated in electrodeposited $\mathrm{Ni}-\mathrm{Co} / \mathrm{WS}_{2}$ nanocomposite coatings [36]. Compared to a pure Ni-P coating, the composite coating showed a reduction in friction coefficient against a steel ball from 0.45 to 0.05 . The authors note the importance of surface activity and water contact angle (Figure 5).

A comparison of direct and pulse plated deposits of nickel-phosphorus alloys has been made, showing the benefits of pulse plating to the morphology and mechanical properties of the deposit in the case of $\mathrm{BN}$ particles in $\mathrm{Ni}$ [31]. 
The importance of a stable dispersion and appropriate attention to particle mixing in the electrolyte before use in electrodeposition, have been stressed, using $\mathrm{Ni}-\mathrm{MoS}_{2}$ deposition as an example [37]. Over the last decade, biomimetic or superhydrophobic/easy-clean such as Ni$\mathrm{P}^{-\mathrm{WS}_{2}}$ [35] and the continuing search for real world applications of graphene and its derivatives, such as graphene oxide which has been studied by brush plating [38], are strong trends.

In an ambitious attempt to facilitate in-situ diagnostic monitoring of coating wear, a luminescent Ni coating, containing an embedded, blue-emitting, rare-earth mixed metal oxide particles of a BAM, doped $\mathrm{BaMgAl}_{11} \mathrm{O}_{17}: \mathrm{Eu}^{2+}$, was electrodeposited from an electrolyte containing a mixture of nonionic and cationic surfactants. The particle content in the deposit could be varied from 0 to 15.6 [40].

A self-lubricating Ni-P-MoS 2 composite coating was deposited on mild steel from a Watts nickel electrolyte and the effects of $\mathrm{MoS}_{2}$ on tribology has been investigated. Compared to a pure Ni-P coating, the Ni-P-MoS 2 composite coating enabled a dramatic reduction in friction coefficient from 0.45 to 0.05 against a steel ball bearing. Surface analysis of the wear scar and wear debris showed minimum wear and oxidation compared to the severe wear and oxidation observed in the pure Ni-P coating. The importance of $\mathrm{MoS}_{2}$ particle history during sliding wear was elucidated [34].

A low-friction, superhydrophic Ni-P-WS 2 coating was achieved in a single-step electrodeposition [35]. By adjusting the particle and surfactant concentrations, a hierarchical surface of micron-sized protrusion arrays and submicron-sized bumps on the top, which 
showed a high water contact angle of $157 \mathrm{deg}$. Mechanical and friction properties are characterized; a sufficient $\mathrm{WS}_{2}$ incorporation in the Ni-P matrix enabled a friction coefficient of 0.17 due to the formation of a self-lubricating tribofilm.

Superhydrophobic and self-cleaning coatings have attracted continued attention for corrosion resistance and ease of maintenance. A superhydrophobic composite electrodeposit based on Ni$\mathrm{WS}_{2}$ on a mild steel substrate has been deposited from a Watts nickel bath containing the cationic surfactant CTAB [33]. At room temperature $\left(22^{\circ} \mathrm{C}\right)$, the deposit had good self-cleaning and corrosion resistance, with a water contact angle above $158 \mathrm{deg}$ and a sliding angle of $<8 \mathrm{deg}$.

Robust surfaces based on nickel-WC were electrodeposited, which showed superhydrophobicity after stearic acid treatment [36]. The coatings achieved a maximum contact angle of water of 164.3 deg with a sliding angle close to zero. By controlling the deposition conditions, versatile coatings were produced. The surfaces showed excellent abrasion resistance and water-repellence. Nonfluorinated superhydrophobic surfaces are important due to increasing environmental pressure to avoid persistent fluorocarbons. The combination of hard, wear resistant and soft, selflubricating layered particles in a metal matrix is rarely considered, yet powerful, in engineering applications. Nonfluorinated superhydrophobic Ni/WC/WS 2 composite coatings with high abrasive resistance have been reported [38].

$\mathrm{Ni} / \mathrm{BN}$ and $\mathrm{Ni} / \mathrm{WS}_{2}$ composite coatings were electrodeposited from an additive-free Watts bath agitated by ultrasound [41]. Under lubricated conditions, the performance of the Ni/BN composite coating was very similar to the benchmark Ni coating, whereas the $\mathrm{Ni} / \mathrm{WS}_{2}$ not only showed a lower coefficient of friction but also prevented the occurrence of stick-slip 
motion that was clearly observed in the other coatings. Under non-lubricated conditions, the incorporation of $\mathrm{WS}_{2}$ particles into the Ni coating not only resulted in a lower coefficient of friction but also helped prevent coating failure.

\subsection{Electrical and electrode materials}

The incorporation of particles into an electrodeposited metal can modify electrical conductivity, lower contact resistance and enhance electrocatalytic activity, contributing to a wide range of electrical and electrochemical uses.

Ni-graphite coatings have been studied for use as electrical feeders in batteries and fuel cells. A Watts bath containing a proprietary surfactant has been studied in a flow cell [42]. Most contributions on electrodeposition of composites aim to obtain a high particle loading in the deposit but the authors sought to achieve a surface with separated, particles of graphite particles which were uniformly dispersed. While appropriate electrolyte conditions were acknowledged, the importance of graphite concentration in the electrolyte and the need for efficient and uniform mass transport over the whole cathode surface were seen as key parameters.

$\mathrm{Ti}_{2} \mathrm{AlC}$ and $\mathrm{Ti}_{3} \mathrm{AlC}_{2}$ particles have been codeposited in copper for use as arc-resistant contacts in electrical switchgear [43]. The micrometre sized particles were incorporated up to $3 \mathrm{wt} \%$ in the copper matrix. Coating hardness, contact resistance and crystallographic structure were investigated in a $50 \mu \mathrm{m}$ thick deposit.

Core-shell multi-dimensional hybrid nanoarchitectures of $\mathrm{Co}(\mathrm{OH})_{2}$ nanoparticles/ $\mathrm{Ni}_{3} \mathrm{~S}_{2}$ nanosheets grown on $\mathrm{SiC}$ nanowire networks have been studied as promising, highperformance asymmetric supercapacitors [44]. The $\mathrm{SiC}-\mathrm{Co}(\mathrm{OH})_{2} / \mathrm{Ni}_{3} \mathrm{~S}_{2}$ hybrid electrode 
showed a specific capacitance of $2318 \mathrm{~F} \mathrm{~g}^{-1}\left(2.56 \mathrm{~F} \mathrm{~cm}^{-2}\right)$ at a current density of $6 \mathrm{~mA} \mathrm{~cm}^{-2}$ and a rate capability of ca. $86 \%$ at $20 \mathrm{~mA} \mathrm{~cm}^{-2}$.

Nanostructured Pt, PtNi and PtCo electrodes have been explored as a PEM fuel cell gas diffusion electrode, GDE. The catalyst nanoparticles were deposited as a low loading on the microporous layer of a carbon GDE by pulse electrodeposition. The substrate was plasma etched as a pretreatment to achieve a homogenous fine-grained deposit morphology [45].

\subsection{Specialised applications}

It is generally found that incorporation of particles improves the corrosion protection value of coatings. The ultrasound assisted electrodeposition of $\mathrm{Zn}$ and $\mathrm{Zn}-\mathrm{TiO}_{2}$ coatings has been described [46]. In the case of zinc deposits, stabilised polymeric micelles, based on polypropylene oxide (core) and poly-ethylene oxide (shell) structures, have been used to realize improved corrosion resistance of composite zinc coatings [47]. Electrodeposited chromium silver nanoparticle composite coatings have been produced for their antibacterial activity [48] although the environmental presence of chromium would seem problematic.

The wear and corrosion resistance of AZ91 magnesium alloy was improved by electrodepositing a Ni- $\mathrm{Al}_{2} \mathrm{O}_{3}$ nanocomposite coating using pulsed current [49]. The effect of operating parameters on the electrodeposition of a Ni coating containing Ti nanoparticles has been considered, with a view to using the deposits for improved high temperature corrosion resistance [50]. The use of ultrasound was claimed to prevent agglomeration of the particles, leading to a more uniform distribution of higher Ti content. Microstructural defects were seen 
in the Ni deposit but could this could be limited by increasing the current density or using pulsed current.

The metal matrix microstructure at the matrix/particle interface in electrodeposited $\mathrm{Cu}$ Diamond composite coatings was found to undergo a transition from large grain/columnar to fine grained/equiaxed when the diamond particle size was reduced [51]. COMSOL simulation suggested that this microstructure transition was due to an increase in the local current density near smaller diamond particles. The change of microstructure modified the thermal conductivity of the composite coating for its application as a heat sink material.

This review has focused on the cathodic deposition of particles incorporated into a metal matrix. Other important examples of composite electrodeposition include:

a) electroless deposition of copper on a polyester fabric for suppression of electromagnetic interference in aircraft [52],

b) anodic deposition of a conductive polymer (polypyrrole) containing ceramic, titanate nanotubes for corrosion protection of steel, e.g., [53],

c) Ni-P and $\mathrm{TiO}_{2}$ codeposition on a silk textile using supercritical $\mathrm{CO}_{2}$ promoted electroless plating for flexible and wearable photocatalytic devices [54], and

d) incorporation of WC particles into a plasma electrolytic oxidation (PEO) coating on AZ31B magnesium alloy for improved corrosion and wear resistance [55].

\subsection{Developments in composite electrodeposition}


Early progress in electrodeposited composite coatings has been dominated by interest from aerospace, transport and heavy engineering. The last decade has seen major progress, encouraged by the availability of newer and nanostructured materials. Developing applications include a) superhydrophobic surfaces offering efficient tribology, good corrosion/wear resistance and improved self-cleaning and b) coatings containing mixed functional particles for specialised engineering. The following trends can be noted:

1. More attention to the quality of particle dispersion in the bath, such as measurement of settling times, optical scattering, particle size distribution, zeta potential and particle charge.

2. More widespread use of nanoparticles, rather than submicron ones, facilitating particle dispersion in baths, resulting in superior wear and corrosion resistant coatings.

3. Improved electrolyte agitation via, e.g., ultrasound, jet eductors, submerged jet impingement and flow cells.

4. Enhanced deposit hardness and tribological properties by the introduction and wider use of ceramic particles such as WC, BDD, $\mathrm{B}_{4} \mathrm{C}$ and h-BN.

5. Coatings presenting a low coefficient of friction against steel and stainless steel counterbodies and self-lubrication, due to improved incorporation of traditional particles such as graphite and PTFE or introduction of more recent 2D layered particles, e.g. graphenes, $\mathrm{MoS}_{2}$ and $\mathrm{WS}_{2}$.

6. Superhydrophobic/self-cleaning surfaces achieved by deposition of textured coatings and those incorporating silicones, fatty acids, PTFE, or $\mathrm{WS}_{2}$.

7. The use of pulsed current to improve electrocrystallisation and morphology, to achieve smaller grain size, better engineering properties and the ability to use higher currents to realise faster electrodeposition. 
8. Speciality, in-situ contact with the cathode surface, e.g., mild abrasion/polishing of the growing deposit using an ultrasonic brush, providing effective local flow and a better deposit morphology.

9. Mixed particle deposits, in an attempt to combine characteristics, e.g., PTFE and SiC or WC and $\mathrm{MoS}_{2}$.

10. Use of metal alloy matrices, such as Ni-P (which can be hardened by subsequent heat treatment) or Ni-Co (which can offer improved corrosion and thermal oxidation resistance.

11. Further exploration of specialised, competitive routes, such as electroless deposition.

12. Consideration of coatings which offer an improved corrosion protection due to less through-porosity or a more concerted surface coverage and less penetrable barrier layer.

\section{Conclusions}

1. The electrodeposition of metallic, ceramic or polymeric particles embedded in a metal matrix has become a mature technology which continues to evolve and diversify.

2. It is well established that metal deposition takes place according to Faraday's laws of electrolysis. The particles transport to the cathode by a combination of electrophoresis and convective-diffusion.

3. The large number of operational variables have interrelated effects on deposit composition and quality.

4. Much of the literature has focused on empirical studies of engineering coatings for wear cutting/drilling/grinding tools (e,g, Ni-SiC) or tribological applications (e.g. Ni-PTFE). 
5. The field has widened with the introduction of electronic materials, electrocatalytic coatings or electrode materials for batteries, fuel cells and supercapacitors.

6. Over the last decade, marked trends have included biomimetic or superhydrophobic/easyclean finishes (e.g. Ni-P-WS $_{2}$ and the continuing search for real world applications of graphene and its derivatives (e.g. Ni-graphene oxide).

7. Despite its importance to deposit quality, characterisation of surface charge and particle dispersion in the electrolyte has been slow.

8. Advances in our understanding of the mechanism of composite electrodeposition have been relatively slow as has the development of adequate multi-physics computer models capable of predicting deposit characteristics from known operational conditions.

\section{Critical areas for further $R \& D$}

In order to rapidly progress the field of electrodeposited composite coatings of particles included in a metal matrix, it is important to make further advances in the following aspects:

1. Quality of particle dispersion in the electrolyte and its characterisation. Including adsorption of species, zeta potential, electrical charge and size distribution. Adsorption isotherms should be used to establish surface coverage of adsorbed surfactants on the particle surface.

2. Judicious combination of particle types and sizes can be to achieve novel, multifunctional coatings.

3. The electrode geometry should be tailored to achieve an effective reaction environment near the cathode, including effective flow velocity together with uniform current, concentration and potential distributions. 
4. The mechanism of electrodeposition of composite layers needs to be updated to consider different types of rate control, flow conditions, particle characteristics and diverse operational variables.

5. Improved multi-physics computer modelling is needed to predict deposit particle composition and characteristics from a knowledge of bath composition and operational variables.

6. Environmental considerations dictate a move away from persistent surfactants, a knowledge of bath and deposit recycling and adequate disposal of products at their end of life.

7. Adequate preparation of a stable particle-bath suspension can necessitate the use of high shear mixing or ultrasonics.

8. Attention to industrial processing and scale-up means that laboratory studies must be designed to have well-defined flow and good experimental design to quantify the importance of operational variables, rather than be centred on convenient but poorly defined reaction environments, such as vertical plate electrodes in a magnetically stirred beaker.

\section{References}

1. C.T.J. Low, F.C. Walsh, Electroplated multifunctional and nanostructured coatings, Ch. 7 in R.J.K. Wood, (Ed), Multifunctional Materials for Tribological Applications, Pan Stanford, 2014, pp. 227-258.

2. F. C. Walsh, Modern developments in electrodes for electrochemical technology and the role of surface finishing, Trans IMF, 97 (2019) 28-42.

*3. M. Musiani, Electrodeposition of composites: an expanding subject in electrochemical materials science. Electrochim Acta, 45 (2000) 3397-3402.

A review highlighting progress and electrochemical applications. A concise review of contemporary knowledge in the electrochemistry of composite coating deposition. 
4. J.L. Stojak, J. Fransaer, J.B. Talbot, Review of electrodeposition, in: R.C. Alkire, D.M. Kolb (Eds.), Advances in Electrochemical Science and Engineering, Vol 7 (2001) 193223., Wiley-VCH Verlag, Weinheim.

5. A. Hovestad, L.J.J. Jannsen, Electrodeposition of metal matrix composites by codeposition of suspended particles, in B.E. Conway (Ed) Modern Aspects of Electrochemistry, No 38 (2005) 475-486.

**6. F.C. Walsh, C. Ponce de León, A review of the electrodeposition of metal matrix composite coatings by inclusion of particles in a metal layer: an established and diversifying coatings technology, Trans IMF, 92 (2014) 83-98.

This extensive review considers the history, technology, and applications of electrodeposited metal matrix-included particles deposits together with a forward look at developing needs.

*7. C.T.J. Low, R.G.A. Wills, F.C. Walsh, Electrodeposition of composite coatings containing nanoparticles in a metal deposit, Surface \& Coatings Technology, 201 (2006) 371-383.

A major review of nanosized particles included in composite deposits by electrodeposition; includes mechanism, electrode geometry, effect of operational conditions and uses.

8. N. Malatji, P.A.I. Popoola, Tribological and corrosion performance of electrodeposited nickel composite coatings, Ch. 10 in Electrodeposition of Composite Materials, A.M.A Mohamed, T.G. Golden, eds, Intech, 2016; http://dx.doi.org/10.5772/62170

9. K. Helle, F.C. Walsh, Electrodeposition of dispersion composite coatings based upon polymer and ceramic particles in a metal matrix, Trans. IMF, 75 (1997) 53-58.

10. C. Kerr, B.D. Barker, F.C. Walsh, J. Archer, The electrodeposition of composite coatings based on metal matrix-included particle deposits, Trans. IMF, 78 (2000) 171-178.

11. C.T.J. Low, F.C. Walsh, Self-lubricating metal composite coatings by electrodeposition or electroless deposition, Encyclopedia of Advanced Tribology, Ed L. Wang, Springer, (2011).

12. Y.H. Ahmad, A.M.A. Mohamed, Electrodeposition of nanostructured nickel-ceramic composite coatings: a review, Int. J. Electrochem. Sci., 9 (2014) 1942-196313. 
13. A.K. Hussain, U.M. Basheer Al Naib, Recent developments in graphene based metal matrix composite coatings for corrosion protection application: a review, Journal of Metals, Materials and Minerals, Vol. 29 (2019) 1-9.

14. A. Lelevich, F.C. Walsh, Electrodeposition of Ni-P composite coatings: a review, Surface and Coatings Technology, (2019); doi.org/10.1016/j.surfcoat.2019.07.027.

15. A. Karimzadeh, M. Aliofkhazraei, F.C. Walsh, A review of electrodeposited Ni-Co alloy and composite coatings: microstructure, properties and applications, Surface and Coatings Technology, 372 (2019) 463-498.

16. M. Paunovich, M. Schlesinger, eds, Modern Electroplating, 5th edn, Hoboken, Wiley, New Jersey, (1990).

17. D. Pletcher, F.C. Walsh, Industrial Electrochemistry, $2^{\text {nd }}$ edn, Chapman and Hall,

18. L. Besra, M. Liu, A review on fundamentals and applications of electrophoretic deposition (EPD). Progress in Materials Science, 52 (2007) 1-61.

19. I. Corni, M.P. Ryan, A.R. Boccaccini, Electrophoretic deposition: from traditional ceramics to nanotechnology. Journal of the European Ceramic Society, 28 (2008) 13531367.

20. N. Guglielmi, Kinetics of the deposition of inert particles from electrolytic baths, J Electrochem. Soc., 119 (1972) 1009-1012.

21. J-P. Celis, J.R. Roos, C. Buelens, A mathematical model for the electrolytic codeposition of particles with a metallic matrix, J. Electrochem. Soc., 134 (1987) 1402-1408.

22. J.L. Valdes, Electrodeposition of colloidal particles, J. Electrochem. Soc., 133 (1987) 223C-228C.

23. B. Lociewitz, Electrodeposition mechanism of composite coatings, Solid State Phenomena, 228 (2015) 65-78.

24. S.C. Wang, N. Zhou, F.C. Walsh, Diverse electrodeposits from modified acid sulphate (Watts nickel) baths, Trans. IMF, 94 (2016) 274-282. 
25. A.M. Rashidi, M. Packnezhad, M. Moshrefi-Torbati, F.C. Walsh, Erosion-corrosion synergism in an alumina/seawater nanofluid, Microfluids \& Nanofluids, 17 (2013) 225232.

26. C.T. Low, C. Ponce-de-León, F.C. Walsh, The rotating cylinder electrode (RCE) and its application to the electrodeposition of metals, Australian Journal of Chemistry, 58 (2005) 246-262.

27. F.C. Walsh, G. Kear, A.H. Nahlé, L.F. Arenas, J.A. Wharton, The rotating cylinder electrode for studies of corrosion engineering and protection of metals. An illustrated review, Corr. Sci., 123 (2017) 1-20.

**28. N. Zhou, S. Wang, F.C. Walsh, Effective particle dispersion via high-shear mixing in electroplated nickel-molybdenum disulphide composite coating for improved tribological performance, Electrochim Acta, 238 (2018) 568-577.

The hydrophobic nature of $\mathrm{MoS}_{2}$ presents a challenge to electrodeposition of composite coatings due to particle agglomerates present in an aqueous plating bath. Electrolyte preparation using high-shear mixing is shown to be an effective way to achieve a narrow particle-size distribution and stable particle dispersions. The Ni-MoS 2 coating had a compact structure and realised a lower coefficient of friction and enhanced wear resistance in unlubricated wear tests, compared to deposits from magnetic stirred electrolytes.

29. F.C. Walsh, C.T. Low, J.O. Bello, Influence of surfactants on electrodeposition of a Ninanoparticulate SiC composite coating, Trans IMF, 93 (2015) 147-156.

30. Y. Zhou, F.Q. Xie, X.Q. Wu, W.D. Zhao, X. Chen, A novel plating apparatus for electrodeposition of Ni-SiC composite coatings using circulating-solution co-deposition technique, Journal of Alloys and Compounds, 699 (2017) 366-377.

31. R. Bernasconi, F. Allievi, H. Sadeghi \& L. Magagnin, Codeposition of nickelphosphorus alloys reinforced with boron carbide microparticles: direct and pulse plating, Trans IMF, (2017)

32. E. Pompei, L. Magagnin, N. Lecis, P.L. Cavallotti, Electrodeposition of nickel-BN composite coatings, Electrochim Acta, 54 (2009) 2571-2574

33. K. Myoshi, Solid lubricants and coatings for extreme environments: state-of-the-art survey, Glenn Research Center, Cleveland, Ohio, 2007. 
*34. G. Zhao, Y. Xue, Y. Huang, Y. Ye, F.C. Walsh, J. Chen, S. Wang, One-step electrodeposition of a self-cleaning and corrosion resistant $\mathrm{Ni} / \mathrm{WS}_{2}$ superhydrophobic surface, RSC Advances, 6 (2016) 59104-59112.

A superhydrophobic composite electrodeposit of tungsten disulphide nanoparticles dispersed in nickel on a mild steel substrate was developed, having a water contact angle over 158 deg and a sliding angle below $8 \mathrm{deg}$.

*35. Y. He, S.C. Wang, F.C. Walsh Y.-L. Chiu, P.A.S. Reed, Self-lubricating Ni-P-MoS 2 composite coatings, Surface and Coatings Technology, 307 (2016) 926-934.

A low-friction, superhydrophic Ni-P-MoS 2 coating was produced by a versatile one-pot, single-step electrodeposition to achieve a hierarchical surface of micron-sized protrusion arrays and submicron-sized bumps with a water contact angle of $157 \mathrm{deg}$.

*36. Y. He, S. Wang, W. Sun, P.A.S. Reed, F.C. Walsh, Synthesis and properties of electrodeposited $\mathrm{Ni}-\mathrm{Co} / \mathrm{WS}_{2}$ nanocomposite coatings, Coatings, 9 (2019) 158-160.

The friction coefficient of $7.9 \%$ wt $\mathrm{MoS}_{2}-\mathrm{Ni}-\mathrm{P}$ composite coatings sliding again steel in air exhibited a steady-state value of 0.05 during a 1-hour reciprocating test, which is almost one grade lower than that of 0.45 of a Ni-P coating. The concentration of $\mathrm{MoS}_{2}$ particles in the electroplating bath had a significant effect on surface roughness and particle loading in the deposit. On the Ni-P-MoS 2 coating, uniform and compact tribofilms abundant in $\mathrm{MoS}_{2}$, were observed on both the coating surface and the steel counter ball, protecting the coating from oxidation.

*37. G. Zhao, J. Li, Y. Huang, L. Yang, Y. Ye, F.C. Walsh, J. Chen, S. Wang, Robust Ni/WC superhydrophobic surfaces by electrodeposition, RSC Advances, 7 (2017) 44896-44903.

The importance of a stable dispersion and appropriate attention to particle mixing in the electrolyte before its use in electrodeposition, are highlighted using $\mathrm{Ni}-\mathrm{MoS}_{2}$ deposition as an example.

38. G. Jin, D. Zhang, M. Liu, X. Cui, E. Liu, Q. Song, C. Yuan X. Wen, Y. Fang, Microstructure, deposition mechanism and tribological performance of graphene oxide reinforced Fe composite coatings by electro-brush plating technique, Journal of Alloys and Compounds, 801 (2019) 40-48. 
*39. J. Zhou, G. Zhao, J. Li, J. Chen, S. Zhang, J. Wang, S. Wang, F.C. Walsh, Y. Xue, Electroplating of nonfluorinated superhydrophobic Ni/WC/WS 2 composite coatings with high abrasive resistance, Applied Science, 487 (2019) 1329-1340.

Nonfluorinated superhydrophobic surfaces are being developed due to increasing environmental pressure to avoid persistent fluorocarbons. The combination of hard, wear resistant and soft, self-lubricating layered particles) in a metal matrix is rarely considered in engineering applications.

*40 Y. He, S.C. Wang, F.C. Walsh, W.S. Li, L. Heb, P.A.S. Reed, The monitoring of coating health by in-situ luminescent layers, RSC Advances, 5 (2015) 42965-42970.

A luminescent $\mathrm{Ni}$ composite, intended to aid monitoring during wear, which contained an embedded, blue-emitting rare-earth mixed metal oxide, (a doped $\mathrm{BAM}, \mathrm{BaMgAl}_{11} \mathrm{O}_{17}: \mathrm{Eu}^{2+}$ ), was electrodeposited from an electrolyte containing a mixture of nonionic and cationic surfactants. The BAM particle content in the deposit could be varied from 0 to $15.6 \%$.

41. I. Tudela, A.J. Cobley, Y. Zhang, Tribological performance of novel nickel-based composite coatings with lubricant particles, Friction, 7 (2019) 169-180.

42. J. Lapinski, D. Pletcher, F.C. Walsh, The electrodeposition of nickel-graphite composite layers, Surface and Coatings Technology, 205 (2011) 5205-5209.

43. R. Grieseler, M.K. Camargo, M. Hopfelda, U. Schmidt, A. Bund, P. Schaaf, CopperMAX-phase composite coatings obtained by electro-co-deposition: A promising material for electrical contacts, Surface \& Coatings Technology, 321 (2017) 219-228.

44. J. Zhao, Z. Li, X. Yuan, T. Shenb, L. Lin, M. Zhang, A. Meng, Q. Li, Novel core-shell multi-dimensional hybrid nanoarchitectures consisting of $\mathrm{Co}(\mathrm{OH})_{2}$ nanoparticles/ $\mathrm{Ni}_{3} \mathrm{~S}_{2}$ nanosheets grown on $\mathrm{SiC}$ nanowire networks for high-performance asymmetric supercapacitors, Chemical Engineering Journal, (2019).

45. A. Egetenmeyer, M. Baumgärtner, T. Linckh, D. Durneata, H. Natter, R. Hempelmann, I. Radev \& V. Peinecke (2017) Pulse electrodeposition of catalyst nanoparticles for application in PEM fuel cells, Trans IMF, 95 (2017) 9-19.

46. M.K.Camargo, I. Tudela, U. Schmidt, A.J. Cobley, A. Bund, Ultrasound assisted electrodeposition of $\mathrm{Zn}$ and $\mathrm{Zn}-\mathrm{TiO}_{2}$ coatings, Electrochim. Acta, 198 (2016) 287-295. 
47. N. Boshkov, N. Boshkova, Application of PEO75PPO30PEO75 stabilised polymeric micelles for improved corrosion resistance of composite zinc coatings, Trans IMF, 95 (2017) 316-320.

48. A. Mendez-Albores, S.G. Gonzalez-Arellano, Y. Reyes-Vidal, J. Torres, S. Talu, B. Cercado, G. Trejo, Electrodeposited chrome/silver nanoparticle (Cr/AgNPs) composite coatings: characterization and antibacterial activity, Journal of Alloys and Compounds, 710 (2017) 302-311.

49. M. Ghamari, A.A. Amadeh, Wear and corrosion resistance of AZ91 magnesium alloy coated by pulsed current electrodeposited $\mathrm{Ni}-\mathrm{Al}_{2} \mathrm{O}_{3}$ nanocomposite, Trans IMF, 95 (2017) 114-120.

50. M. Lekka, R. Offoiach, F. Revelant, L. Fedrizzi, Effect of the plating parameters on the electrodeposition of $\mathrm{Ni}$ matrix coatings containing $\mathrm{Ti}$ nanoparticles, Trans IMF, 97 (2019) 73-81.

51. H.J. Cho, D. Yan, J. Tam, U. Erb, Effects of diamond particle size on the formation of copper matrix and the thermal transport properties in electrodeposited copper-diamond composite materials, Journal of Alloys and Compounds, 791 (2019) 1128-1137.

52. W.F. Qin, Development of metallised polyester fabric by electroless copper for aircraft application using glyoxylic acid as reductant, Trans IMF, 94 (2016) 246-249.

53. P. Herrasti, A.N. Kulak, D.V. Bavykin, C. Ponce de Léon, J. Zekonyte, F.C. Walsh, Electrodeposition of polypyrrole-titanate nanotube composite coatings and their corrosion resistance, Electrochim Acta, 56 (2011) 1323-1328.

54. H. Nasiri Vatan, M. Adabi, Investigation of wear and corrosion resistance of nanocomposite coating formed on AZ31B Mg alloy by plasma electrolytic oxidation, Trans IMF, 95 (2017) 308-315.

55. W.-T. Chiu, Chun-Yi Chen, Tso-Fu Mark Chang, T. Hashimoto, H. Kurosu, M. Sone, $\mathrm{Ni}-\mathrm{P}$ and $\mathrm{TiO}_{2}$ codeposition on a silk textile using supercritical $\mathrm{CO}_{2}$ promoted electroless plating for flexible and wearable photocatalytic devices, Electrochim Acta, 294 (2019) 68-75. 


\section{Figure Captions}

Fig. 1 Interrelated factors involved in composite electrodeposition. After Walsh and Ponce de León [6] with modifications.

Fig. 2 Important aspects of composite electrodeposition.

a) The codeposition of particles and metal by electrodeposition.

b) Interactions among process conditions, operational parameters and deposit properties.

c) Critical factors for successful composite deposits.

d) Factors affecting the mechanism of composite electrodeposition and output results sought from a multi-physics model.

Fig. 3 Major operational variables which affect the deposit. The authors consider that aspects in italics have received insufficient attention in the literature.

Fig. 4 The importance of shear mixing to particle-electrolyte preparation. After Zhou et al [28]. The $\mathrm{MoS}_{2}$ particle Z-average size is shown as a function of a) high-shear mixing speed for $1 \mathrm{~h}, \mathrm{~b}$ ) high-shear mixing time at $8000 \mathrm{rev} \mathrm{min}^{-1}$ compared with a cylindrical bar at 2000 rev $\min ^{-1}$ in magnetic stirring. (c) The zeta potential of $\mathrm{MoS}_{2}$ particles as a function of mixing time.

Fig. 5 The variation in contact angle of water on electrodeposited $\mathrm{Ni}-\mathrm{Co} / \mathrm{WS}_{2}$ coatings as a function of the $\mathrm{WS}_{2}$ particle loading. After He et al [36]. 


\section{Particle}

\section{Operating conditions}

- current density

- temperature

- steady or pulsed current

- bath agitation
- convectivediffusion likely

- adsorbed layer of surfactant

$\leftarrow$ electrophoresis

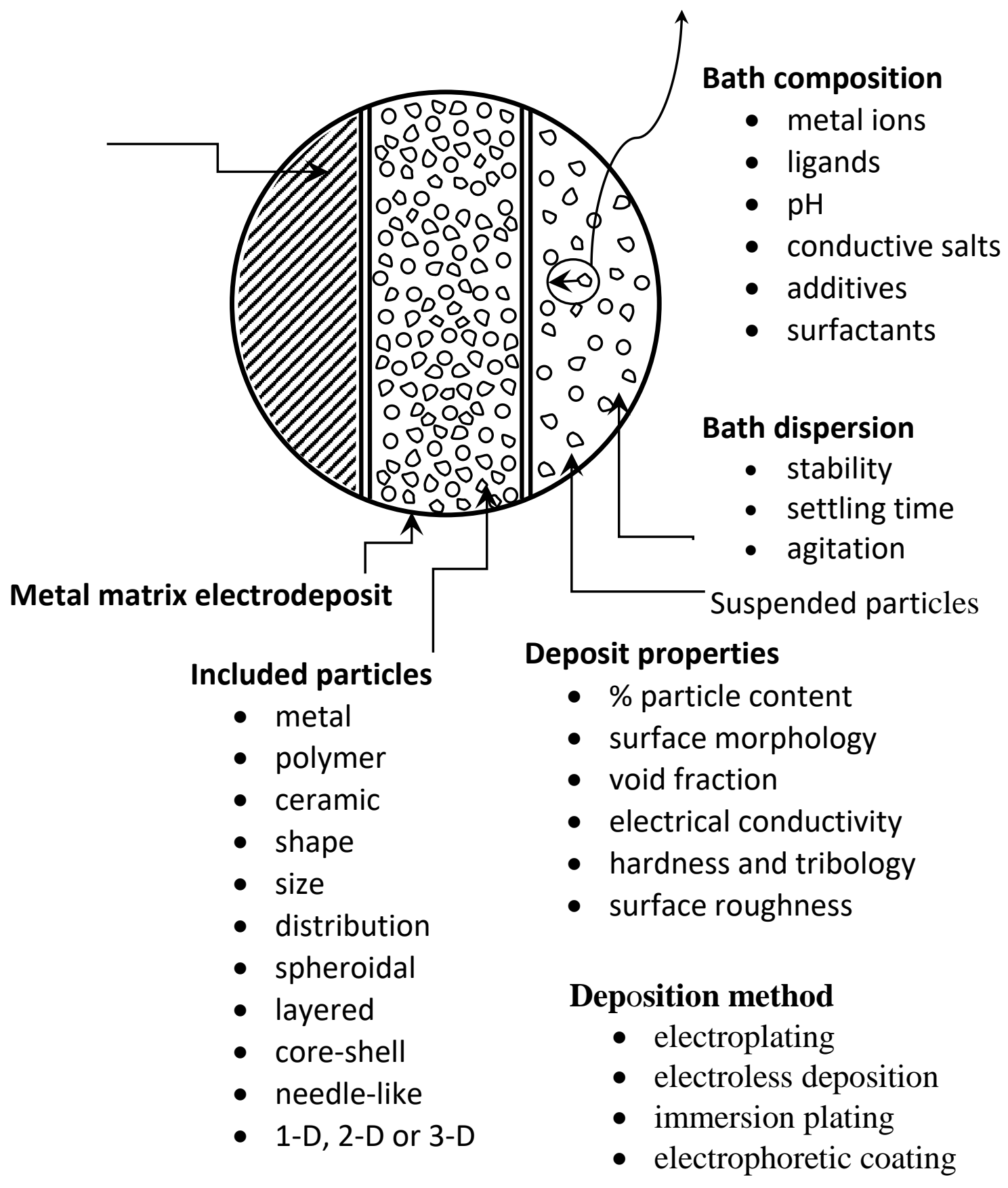

Fig. 1 


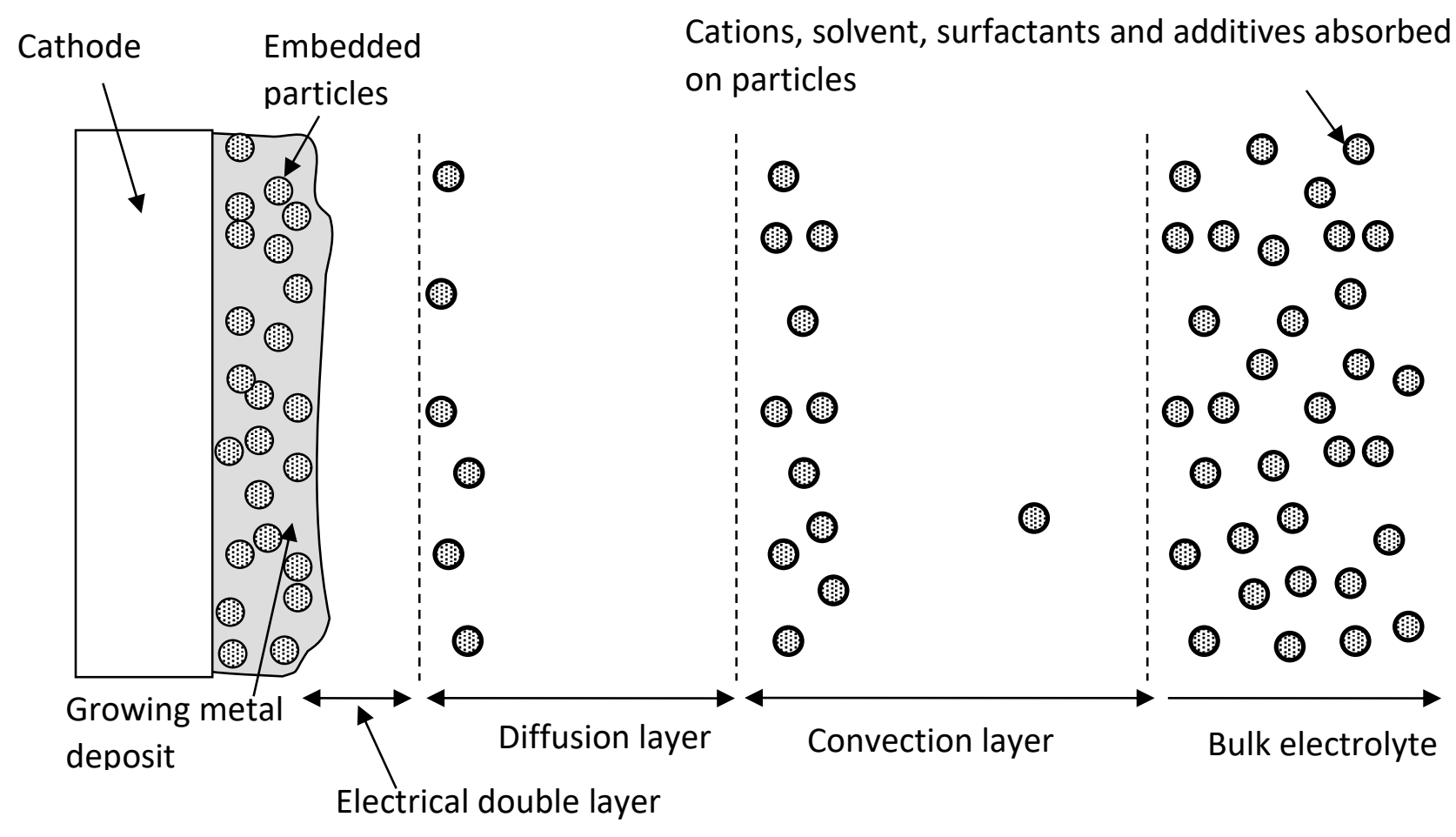

Fig. 2a) 


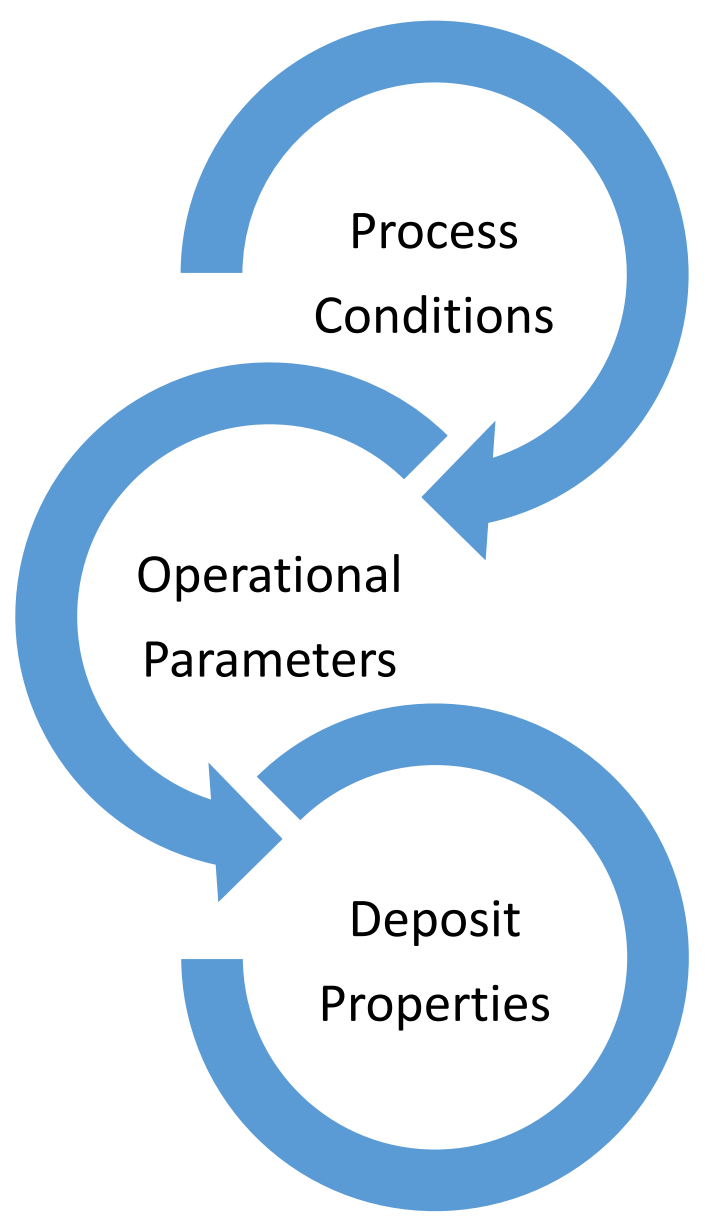

Fig. 2b) 


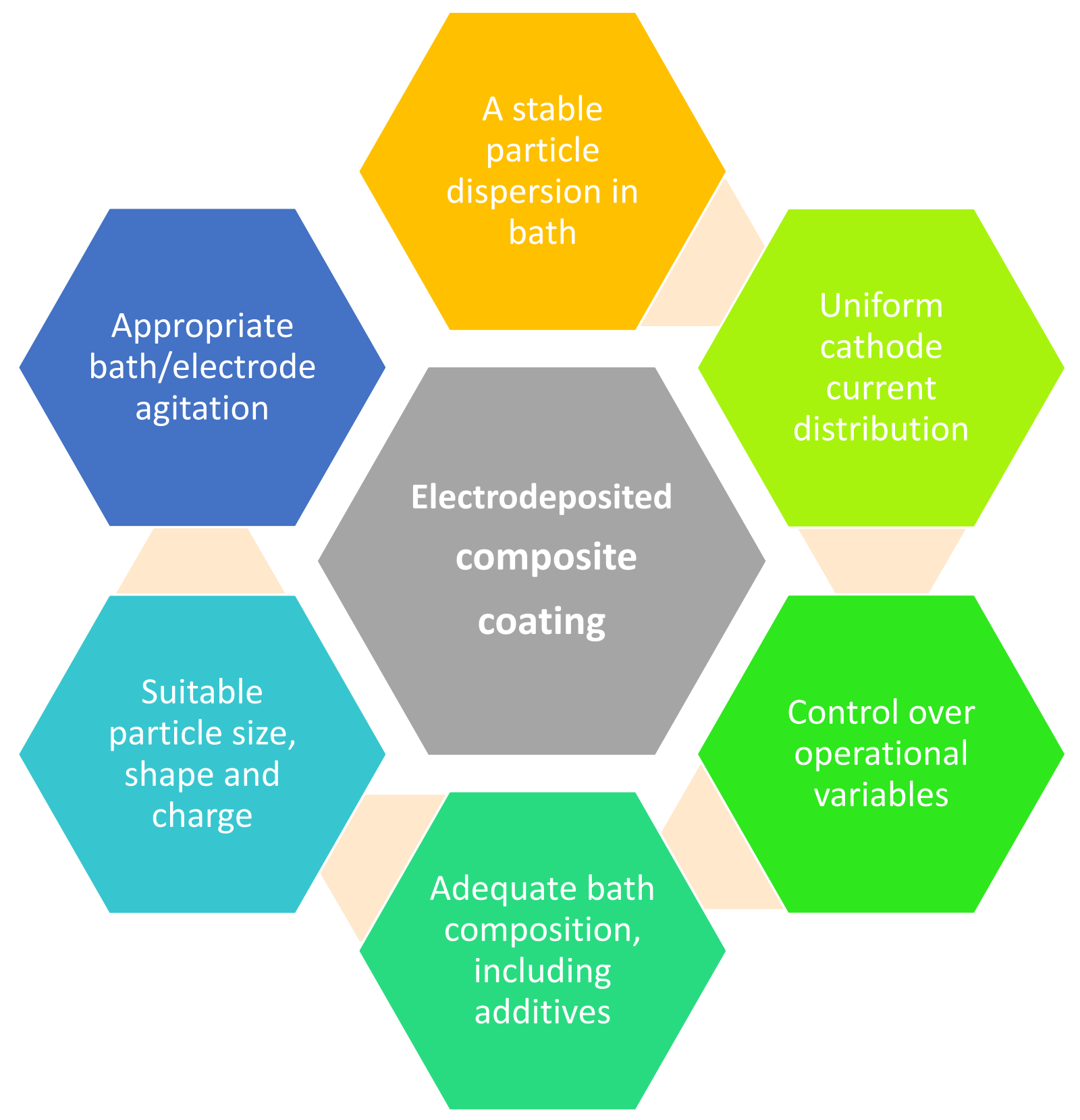

Fig. 2c) 


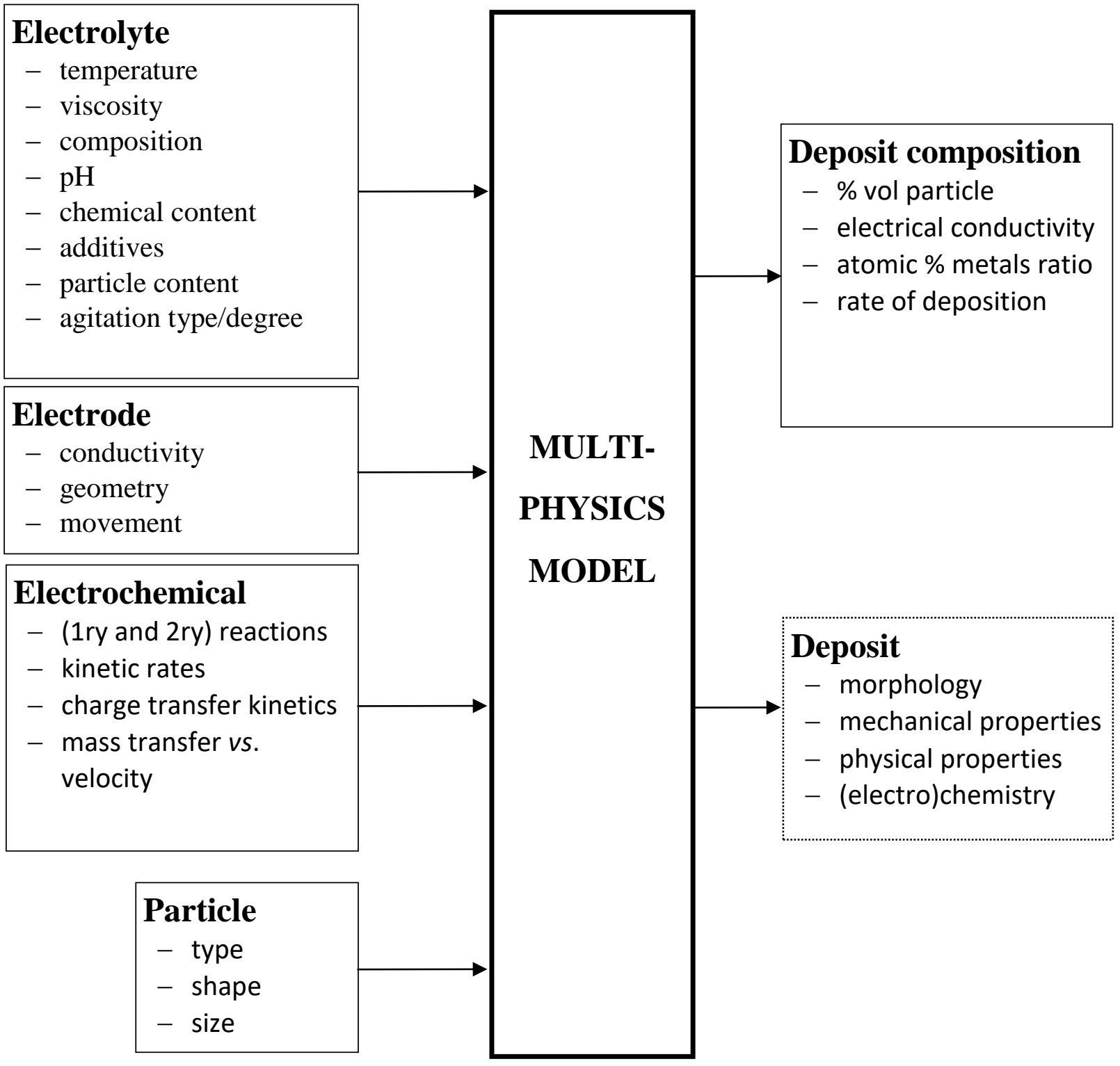

Fig. 2d) 


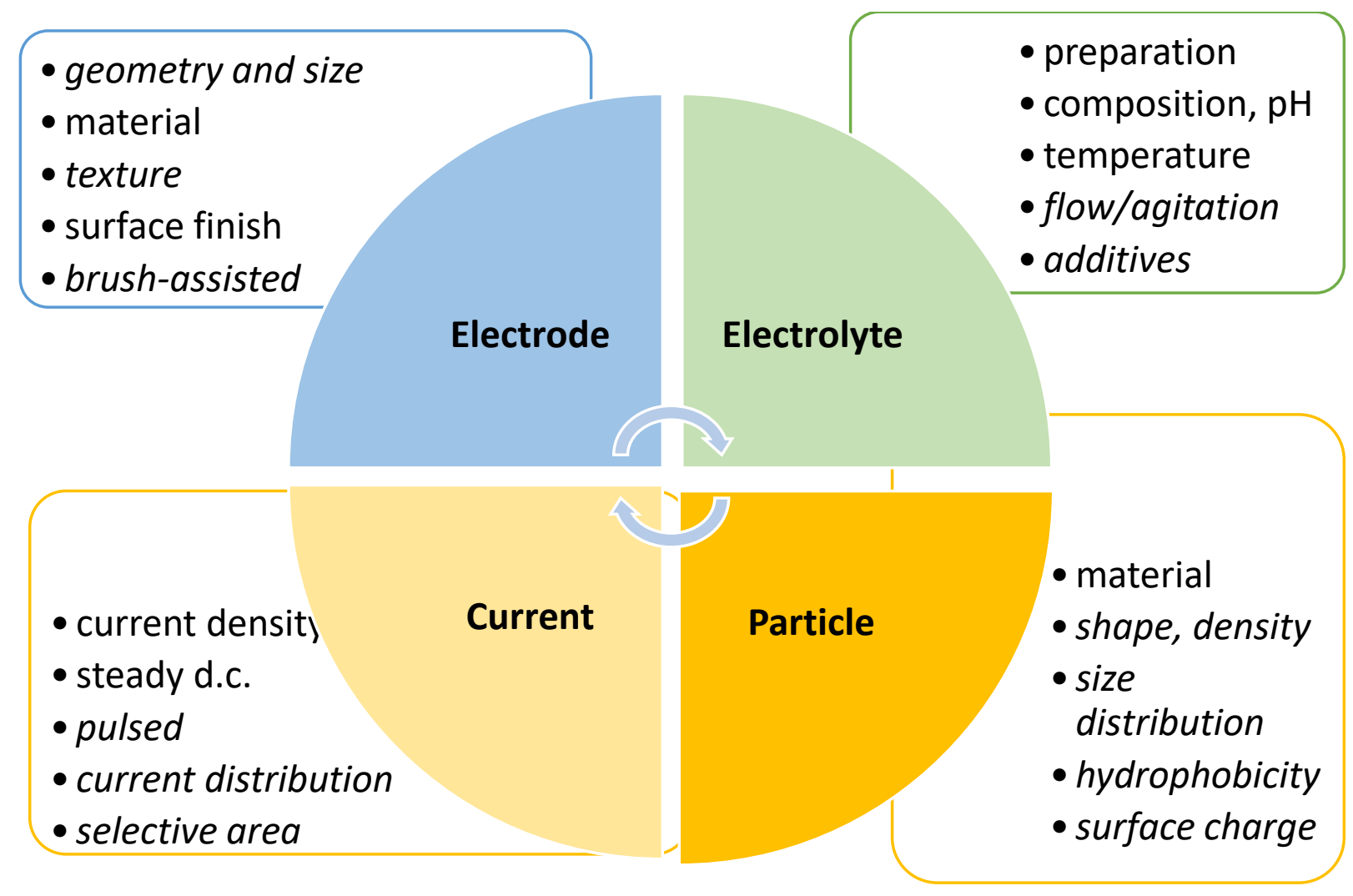

Fig. 3 

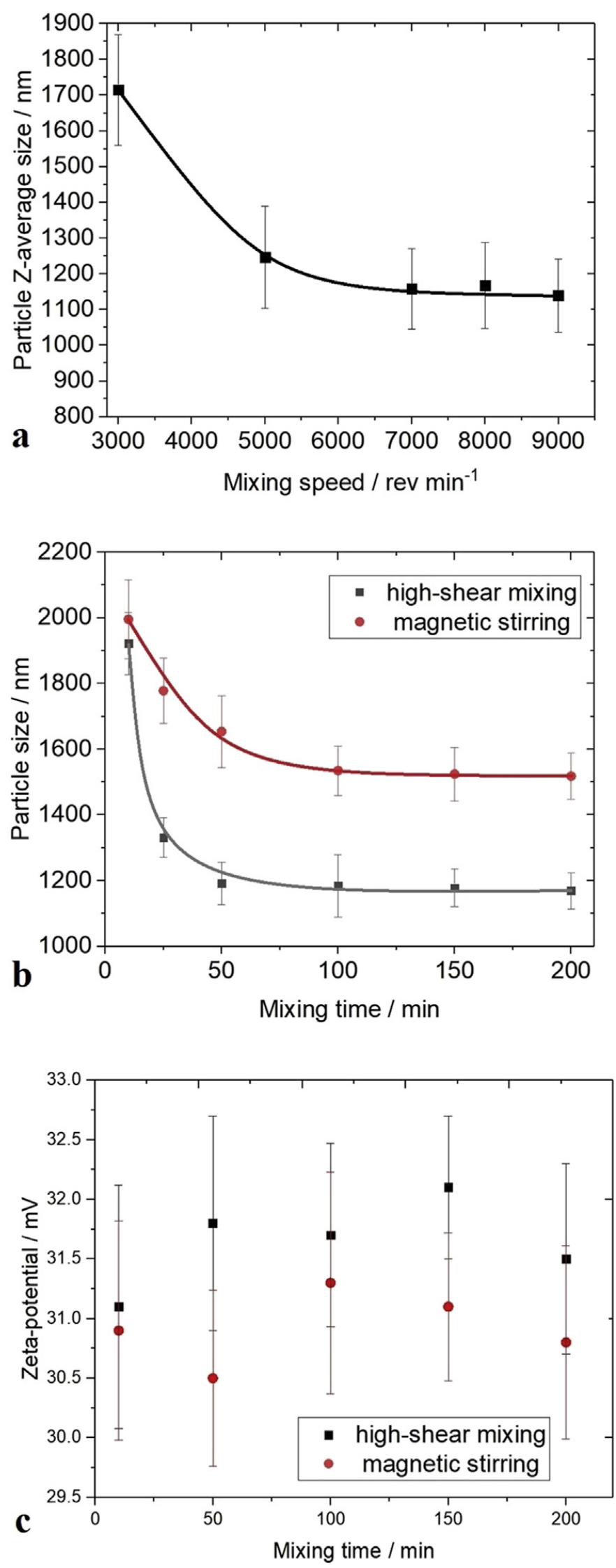

Fig. 4 


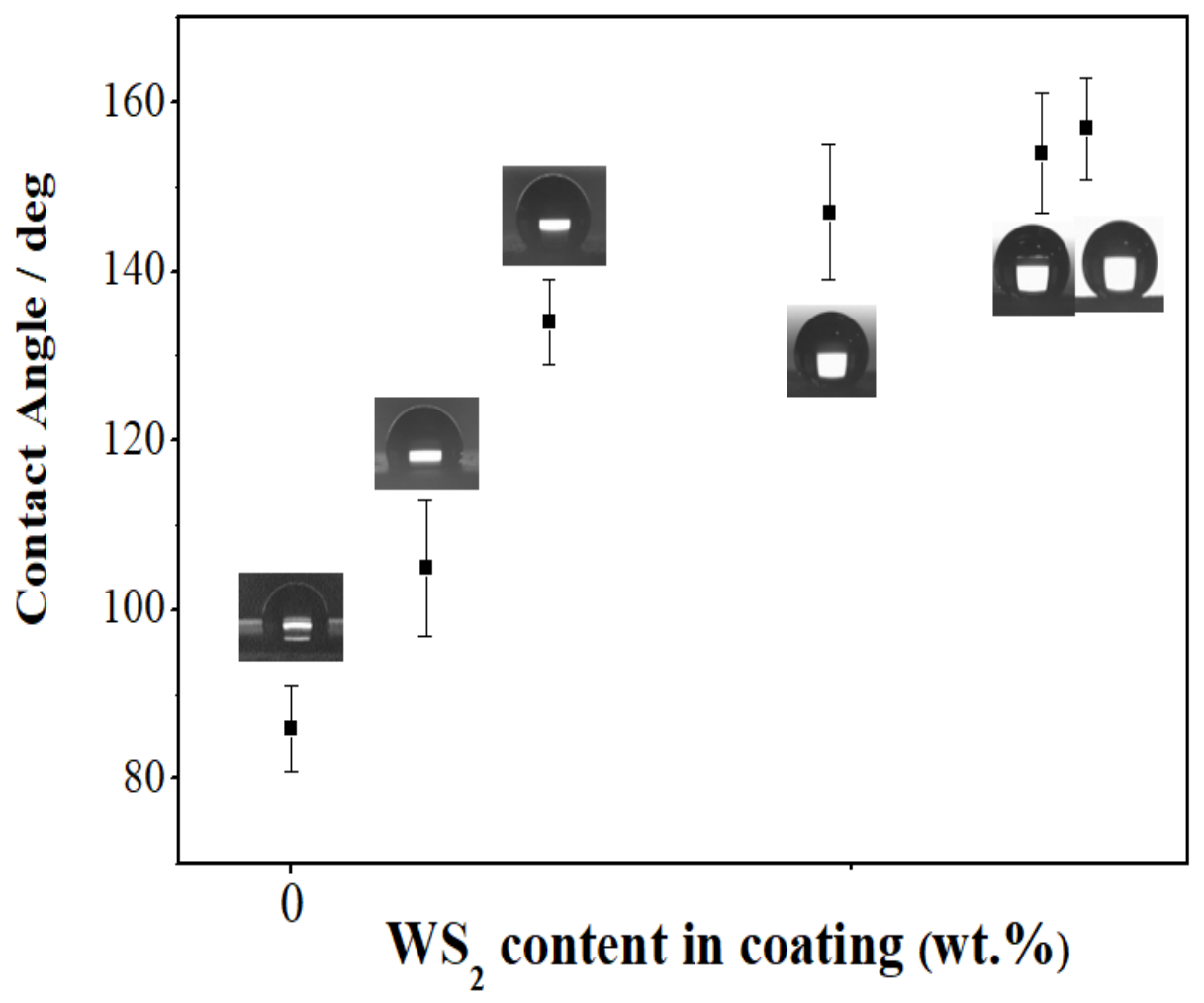

Fig. 5 